\title{
Inventory Optimization of Fresh Agricultural Products Supply Chain Based on Agricultural Superdocking
}

\author{
Lixin Shen $\mathbb{D}^{1},{ }^{1}$ Fucheng Li, ${ }^{1}$ Congcong Li, ${ }^{1}$ Yumin Wang, ${ }^{1}$ Xueqi Qian, ${ }^{2}$ Tao Feng $\mathbb{D},{ }^{3}$ \\ and Cong Wang ${ }^{1}$ \\ ${ }^{1}$ Dalian Maritime University, Dalian, China \\ ${ }^{2}$ Beijing Jiaotong University, Beijing, China \\ ${ }^{3}$ Eindhoven University of Technology, Eindhoven, Netherlands
}

Correspondence should be addressed to Lixin Shen; shenlixin@dlmu.edu.cn

Received 14 July 2019; Revised 3 December 2019; Accepted 18 December 2019; Published 24 January 2020

Academic Editor: Eneko Osaba

Copyright (c) 2020 Lixin Shen et al. This is an open access article distributed under the Creative Commons Attribution License, which permits unrestricted use, distribution, and reproduction in any medium, provided the original work is properly cited.

The "agricultural superdocking" mode which has been strong supported by the government has become the main way for fresh agricultural products to enter the market in China. Based on the analysis of fresh agricultural products supply chain inventory management under the "agricultural superdocking" mode, this paper constructs an integrated inventory model for fresh agricultural products of "farmers' professional cooperatives + distribution centers + supermarkets." Considering multiple members at each echelon of a supply chain, a model that maximizes the overall profit of the supply chain is proposed. The model assumes that the market demand of fresh agricultural products is affected by freshness and sales prices, and the distribution center is responsible for not only storage, processing, and distribution but also coordinating the production and supply information of farmers' professional cooperatives and the order sales information of supermarkets. An improved genetic algorithm is developed to solve the nonlinear optimization problem. Results of a case study show that the optimal supply and replenishment strategy under the given supply chain distribution process are obtained.

\section{Introduction}

Fresh agricultural products are indispensable necessities in people's daily life. Since 2013, the annual growth rate of fresh products market in China has remained above 6\%, and the market scale of fresh products reached 1.91 trillion yuan in 2018. Fresh agricultural products have the characteristics of strong perishability, large circulation loss, high timeliness, and difficult transportation. The traditional multiechelon supply chain mode of "producers of agricultural products + multiechelon processing enterprises (wholesale markets) + retail enterprises" has many circulation links which involve large losses, and the phenomenon of increasing price cannot meet the demand for fresh agricultural products. "Agricultural superdocking" comes to be a new supply chain mode in the way that it omits many intermediate links and can circulate quickly. At present, many companies have adopted the "agricultural superdocking" mode of fresh products supply chain, such as Walmart, Hema Fresh, China Resources Vanguard, and Carrefour. With the strong support of Chinese governments, the "agricultural superdocking" mode has gradually become the main way for fresh agricultural products to enter the market.

The "agricultural superdocking" mode in the paper refers to the "farmers' professional cooperatives + distribution centers + supermarkets" mode, which is the main "agricultural superdocking" mode adopted by developing countries including China. Here, distribution centers mainly refer to third-party logistics service providers who are responsible for the collaborative management production, supply, and order sales, as well as storage and distribution of fresh agricultural products. In this way, farmers' professional cooperatives and supermarkets can focus more on their own production and sales. This paper studies the collaborative inventory management among three-echelon entities under this mode, also known as integrated inventory management. 
In general, the demand and supply of fresh agricultural products fluctuate considerably with climatic variations, seasonal changes, and various social factors [1]; thus, each member in the supply chain should not hold high inventory. Too high or too low inventory will increase procurement costs or lead to lost opportunity costs. Therefore, it is necessary to optimize the integrated inventory of the "agricultural superdocking" mode. The goal of inventory optimization is to determine a reasonable inventory level or replenishment quantity, reduce inventory costs, and improve overall benefit. This paper establishes an integrated inventory model of fresh agricultural products based on "farmers' professional cooperatives + distribution centers + supermarkets" mode. With an objective to maximize the overall profit of the supply chain, the integrated inventory optimization model of fresh agricultural products supply chain based on the "agricultural superdocking" mode is established and examined by adjusting the replenishment and supply strategies between various levels of the supply chain.

\section{Literature Review}

"Agricultural superdocking" has become an important mode of fresh agricultural products supply chain. In recent years, related research on the "agricultural superdocking" mode mainly includes the following aspects: (1) analysis of development status and problems. In practice, the "agricultural superdocking" supply chain has gradually formed multiple modes. Li [2] summarized five types of the "agricultural superdocking" mode: "farmers' professional cooperatives + supermarkets" mode, "farmers' professional cooperatives + distribution centers + supermarkets" mode, "agricultural product bases + leading enterprises of agricultural products + supermarkets" mode, direct sales mode, and joint direct mining mode. The "agricultural superdocking" mode in China is mainly the "farmers' professional cooperatives + distribution centers + supermarkets" mode [3]. Guo and $\mathrm{Xu}$ [4] studied the stability of farmer cooperatives in the "agricultural superdocking"mode and its determinants. The research found that the requirements of supermarkets for agricultural products, the effects of government policies, the capacity of cooperatives, and the level of the regional economy are the most important factors that affect the stability of the "agricultural superdocking" relationship. In the process of "agricultural superdocking," Yang et al. [5] established a multiagent simulation model of the "agricultural superdocking" order default problem based on the development of "agricultural superdocking" in Ningxia Hui Autonomous Region. The study found that the default rate is mainly related to agricultural products prices, agricultural products qualification rates, information transmission mechanisms, and policy support.

Zheng et al. [6] constructed the profit function of the revenue sharing contract for two-stage fresh products supply chain and improved revenue sharing contract. The results showed that the improved revenue sharing contract can promote the information sharing of the fresh products supply chain so that the profit function of the farmers' professional cooperatives and supermarkets will reach the level of Pareto optimal. Yang [7] studied the unequal rights in the "agricultural superdocking" mode from the perspective of contribution degree and alliance position. Based on the modified Shapley value method that considers the weight power index and the average tree solution (A-T solution) that limits the alliance structure, the profit distribution strategy concerning unequal rights is given. Based on the traditional Shapley profit allocation method, Yao and Ran [8] proposed a modified profit allocation method considering risk factors of agricultural supply chain participants. Li and Wang [3] used the revenue sharing contract to coordinate the "agricultural superdocking" supply chain, and the optimal decisionmaking behavior of each member in the coordination mode is obtained. By adjusting the value of the revenue sharing factor, the revenue of the farmers' cooperative and supermarket can achieve Pareto improvement.

Chen et al. [9] studied the relationship between channel opportunistic behavior and farmers' psychological contract under the "agricultural superdocking" mode. The study found that, in the channel relationship, the farmers' transactional psychological contract will promote the generation of opportunistic behavior, and the relational psychological contract will inhibit the generation of channel opportunistic behavior. Fan and Zhang [10] made an empirical analysis on the production and circulation data of agricultural products in Langfang, Hebei province. It is confirmed that, under the guidance of the market and policy, the circulation of fresh agricultural products is gradually moving towards intensification, and making full use of the policy advantages to develop intensive circulation will be the most advantageous way to distribute fresh agricultural products.

Inventory management research includes research on single entity, two-echelon supply chain, and three-echelon supply chain. Wang [11] studied the inventory of singlevariety fruit in fresh supermarkets. According to the perishability and discontinuous demand of fresh fruit, a fruit inventory control model of fresh food supermarket chains was constructed under the conditions of optimal order cycle and optimal price. Wang et al. [12] established a replenishment pricing model in which the deterioration rate obeys the three-parameter Weibull distribution under a random environment. The direct method is used to solve the retailer's optimal inventory strategy and commodity price when the profit is largest. Tang et al. [13] integrated the decisionmaking behavior of strategic consumers, constructed singlestage and two-stage pricing and inventory decision models of retailers, and analyzed the influencing mechanism of fresh agricultural product's value residual rate on consumer's behavior, retailer's optimal pricing, optimal inventory level, and profit. Shen et al. [14] took small and medium enterprises in India as an example to study supplier inventory management. The amount to purchase in the harvest season as well as how much to retrieve for each selling period strongly impact the profit for a wholesaler. Therefore, Liu et al. [15] analyzed the optimal purchase and inventory retrieval quantities for perishable seasonal agricultural products considering the costs of storage, underage and overage, prospects of future prices and demands, and 
product deterioration. Banerjee and Agrawal [16] analyzed the retailer's inventory management strategy and established a model of perishable inventory. The model considers that the demand for perishables is affected by sales prices and freshness. Janssen et al. [17] proposed a microperiodic inventory replenishment policy for quickly perishable goods under stochastic demand, which can be used for perishable items when waste reduction is aimed for.

Aiming at the two-echelon cold chain system which is composed of distribution centers and retailers, Wang et al.[18] introduced freshness efforts and time factors to characterize the quantity and quality loss of fresh agricultural products. Considering that the demand is affected by price and freshness, taking the maximum average profit of the supply chain as the objective function, an integrated twoechelon cold chain inventory model is established to analyze the best freshness input, inventory, and pricing. Mou et al. [19] considered the combined effects of freshness and price on customer demand and the impact of freshness attenuation on the deterioration rate and constructed a deterioration rate function that is jointly affected by the freshness and time of fresh agricultural products. The decentralized decision-making inventory model and the integrated decision-inventory model of the two-echelon cold chain system reveal the impact of freshness and price fluctuations on the cold chain inventory strategy and system profit. Chen and Xiao [20] established a game model for a two-echelon supply chain with one supplier and multiple competing retailers. They studied the pricing decision and the replenishment policy for each member under both a decentralized channel and a centralized channel. Shin et al. [1] proposed a twostage dynamic inventory model for perishables, which aims to minimize the difference between supply and demand under constraints of market consistency and perishability.

Furthermore, Fan [21] established an integrated model which contains a manufacturer, a distribution center, and multiple retailers. The introduction of preservation costs in the integrated model combines product freshness level and fresh investment. The optimal replenishment policy when the integrated inventory profit is the largest is obtained by solving the model. Jiang [22] established an integrated cold chain inventory model which contains multiple manufacturers, a distribution center, and multiple retailers in a finite horizon. The model considered the value-added service of the distribution center, and the deterioration rate obeys the three-parameter Weibull distribution. Dai et al. [23] analyzed a supply chain with one supplier, multiple middlemen, and a retailer and proposed a multiechelon inventory model considering the different needs of the three entities. The goal of the model is to minimize the average inventory cost of each entity. Xu and Feng [24] analyzed the inventory cost of the three-echelon inventory system of fresh agricultural products which contains one manufacturer, multiple distributors, and multiple retailers and then proposed a simulation-based optimization model of the multiechelon inventory system of fresh agricultural products. The effect of commodity prices and freshness on demand is not considered in the model. Tsai and Chen [25] proposed a simulation-based solution framework for tackling the multiobjective inventory optimization problem. The goal is to find appropriate settings of reorder point and order quantity to minimize the expected values of the total inventory cost, the average inventory level, and the expected value of inventory shortage frequency. Ma et al. [26] regarded quantity loss and quality loss as functions of freshness efforts and demand as a function of freshness, price, and other random variables. The paper studied the coordination of three-echelon fresh product inventory under asymmetric information.

In summary, existing literature on the two-echelon supply chain for a single entity is well elaborated. However, in terms of the three-echelon inventory management research, no research addressed on the three-echelon inventory management issue, aiming at a fresh agricultural products supply chain consisting of multiple farmer cooperatives, multiple distribution centers, and multiple supermarkets. In addition, most research assumes that middlemen are responsible only for the storage and distribution of fresh agricultural products and without a function of coordinating production, supply, and sales information. Thus, when optimizing the level of inventory, the in-depth analysis of influential factors of market demand rate is insufficient.

In case of the research of inventory optimization algorithms, Fan [21] established an optimization model for a three-echelon cold chain system consisting of a manufacturer, a distribution center, and multiple retailers. Considering the complexity and nonlinearity of the inventory model, a genetic algorithm is used to solve the model to obtain the optimal replenishment strategy when the integrated inventory profit is maximized. Zhao and Wang [27] verified the feasibility and effectiveness of the simulationbased genetic algorithm optimization method for inventory control under order uncertainty. The simulation-based genetic algorithm method can realize the comprehensive optimization of customer satisfaction of the hybrid supply chain by modifying the inventory control parameters in finite genetic evolution generations. In addition, Mousavi et al. [28] proposed a modified particle swarm optimization for solving the integrated location and inventory control problems in a two-echelon supply chain network. Xu and Feng [24] proposed a simulation-based optimization model of a multiechelon inventory system of fresh agricultural products using the FlexSim simulation software and the improved particle swarm optimization algorithm. Particle swarm optimization algorithm is an effective tool for solving nonlinear continuous optimization problems, combinatorial optimization problems, and mixed-integer nonlinear optimization problems. It has the advantages of simple implementation and fast convergence speed.

In summary, through the research on literatures of inventory management and inventory optimization algorithms, it is found that there is no research on multiagent inventory management of the three-echelon supply chain under the "agricultural superdocking" mode. Therefore, this paper constructs an integrated inventory model of fresh agricultural products supply chain based on the "agricultural superdocking" mode which has multiple members at each 
echelon of the supply chain. The model assumes that the market demand rate is affected by the freshness and the sales price. A distribution center is responsible for storage, processing, and distribution and coordinates the production and supply information of farmers' professional cooperatives and the order sales information of supermarkets. Due to the complexity of the members and echelons of the integrated inventory optimization model, the concavity and convexity of the objective function cannot be judged by direct derivation. Thus, we use a genetic algorithm to solve the problem. At the same time, the genetic algorithm is improved by adding adaptive crossover operators and adopting the elite retention strategy. Further, a catastrophe step is added to prevent the genetic algorithm from premature maturity, falling into a local optimal value. Finally, the validity of the model is proved through a case study.

\section{Model Formulation and Assumptions}

This paper intends to optimize the integrated inventory level of distribution centers represented by third-party logistics service providers in the context of "agricultural superdocking" and analyze the inventory management strategy when multiple supply chain members participate in transportation and distribution of fresh agricultural products. Three stakeholders are taken into account in this three-stage supply chain, which are farmers' professional cooperatives, distribution centers, and supermarket. Farmers' professional cooperatives sell fresh agricultural products to distribution centers, while distribution centers sell them to supermarkets at a price which is higher than their purchase price. In this regard, the supermarkets receive the products from distribution centers for market sales, which end the operation process of the supply chain. The distribution centers are mainly responsible for the processing of fresh agricultural products purchased from farmers' professional cooperatives and the logistics and distribution of the whole supply chain. Farmers' professional cooperatives and supermarkets are only responsible for their respective production and sales tasks and pay the corresponding logistics and distribution costs.

In order to build the model of this three-stage supply chain model for fresh agricultural products, a few assumptions are made as follows:

(1) Each farmers' professional cooperative provides one type of fresh agricultural product

(2) Each supermarket orders at least one type of fresh agricultural product, and the demand rate of fresh agricultural products in supermarkets is dependent on the selling price and the degree of freshness of the products

(3) Without considering lead-time and out-of-stock, the replenishment process is completed instantaneously

(4) The unit time productivity of farmers' professional cooperatives is constant within a limited period of time

(5) Each distribution center must supply products to supermarkets, and there are no distribution centers without supply to any supermarkets after the replenishment from farmers' professional cooperatives

(6) The distribution service is provided by the distribution center, and farmers' professional cooperatives and supermarkets pay the corresponding distribution costs to the distribution center.

In a supply chain system of fresh agricultural products, we assume that the supply chain is composed of $M$ farmers' professional cooperatives, $K$ distribution centers, and $N$ supermarkets. To make the model formulation simplified, the symbols used in the models are listed as follows:

$W$ : a finite time interval defined to study the optimal replenishment strategy.

$n$ : the total number of supermarkets; for the $i^{t h}$ supermarket, $i=1,2, \ldots, n$.

$K$ : the total number of distribution centers; for the $k^{\text {th }}$ distribution center, $k=1,2, \ldots, K$.

$m$ : the total number of farmers' professional cooperatives; for the $j^{\text {th }}$ farmers' professional cooperative, $j=1,2, \ldots, m$. (note: because the model assumes that each farmers' professional cooperative only provides one type of fresh agricultural product, the varieties of fresh agricultural products are also $m$ ).

$a^{j k}$ : the number of times the farmers' professional cooperative $j$ supplies the distribution center $k$ within a limited period of time $w$.

$x_{j k}$ : time interval of supply.

$T_{j k}$ : during the limited period of time $W$, the length of the supply interval that a farmers' professional cooperative $j$ supplies to the distribution center $k$, $T_{j k}=A / a_{j k}, 0 \leq x_{j k} \leq a_{j k}$.

$b_{j k i}$ : the number of times that the distribution center $k$ supplies product $j$ to supermarket $i$ during the supply interval $T_{j k}$. The length of the period of the supply interval $t_{j k i}=T_{j k} / b_{j k i}, 0 \leq z_{j k i} \leq b_{j k i}$.

$\varepsilon_{j}$ : productivity of fresh agricultural products of the farmers' professional cooperative $j$.

$I_{j k}(t), I_{j k}$ : during the supply interval $x_{j k}$, the inventory level at time $t$ and the total stock of the entire supply interval when the product is supplied from farmers' professional cooperative $j$ to the distribution center $k$. $I I_{j k i}^{z_{j k i}}(t), I I_{j k i}^{z_{j k i}}$ : during the supply interval $z_{j k i}$, the inventory level at time $t$ and the total stock of the entire supply interval of the product $j$ in the distribution center $k$ (supply to the supermarket $i$ ).

$I I I_{j k i}(t), I I I_{j k i}$ : during the replenishment interval, the inventory level at time $t$ and the total stock of the entire supply interval of product $j$ in supermarket $i$ (replenishment from the distribution center $k$ ).

$g_{j k i}, g_{j k}$ : single replenishment quantity of product $j$ from distribution center $k$ to supermarket $i$. Single replenishment quantity of product $j$ of distribution center $k$. 
$g_{j k i}^{z_{j k i}}$ : the initial inventory of product $j$ (supply to supermarket $i$ ) in the distribution center $k$ in the supply interval $z_{j k i}$.

$x_{j k i}$ : the total market demand of the product $j$ in the supermarket $i$ (replenishment from distribution center $k$ ) within the replenishment interval.

$P_{j}$ : unit production costs of farmers' professional cooperative $j$.

$P_{j i}$ : unit selling price of product $j$ in supermarket $i$.

$P 1_{j k}, P 2_{j k}, P 3_{j k}$ : unit purchase price, sale price, and processing cost of the product $j$ in distribution center $k$.

$C 1_{j k}, C 2_{j k}$ : distribution cost rate and price rate of unit product $j$ in distribution center $k$.

$f_{j}, d_{j k}, s_{j i}$ : unit inventory cost of fresh agricultural products of farmers' agricultural cooperative $j$, distribution center $k$, and supermarket $i$.

$\theta_{1}, \theta_{2}, \theta_{3}$ : quantitative change coefficient of fresh agricultural products of farmers' agricultural cooperative, distribution center, and supermarket.

$y_{j k}$ : dummy variable of whether distribution center $k$ sends orders to farmers' agricultural cooperative $j$. $y_{j k}=1$ if yes and 0 otherwise.

$y_{k i}$ : dummy variable of whether supermarket $i$ sends orders to distribution center $k . y_{j k}=1$ if yes and 0 otherwise.

$D_{j i}(t)$ : demand rate function of fresh agricultural product $j$ in supermarket $i$.

$U$ : total profits-the sum of profits of all farmers' agricultural cooperatives, distribution centers, and supermarkets.

$d g_{k}, s g_{i}$ : revenue sharing coefficient of distribution center $k$ and supermarket $i$.

$d z_{k}, s z_{i}$ : wholesale price discount rate of distribution center $k$ and supermarket $i$.

The demand rate of fresh agricultural products in supermarkets, $D$, which is dependent on the freshness, selling price, and market demand, can be calculated as follows:

$$
\begin{aligned}
D(t) & =\lambda_{t} \cdot(c-d \cdot p), \\
\lambda_{t} & =\lambda_{1} \cdot e^{-\alpha t}
\end{aligned}
$$

where $\lambda_{1}$ is the freshness of fresh agricultural products when it arrives at the supermarket, $\lambda_{t}$ is the freshness of fresh agricultural products at time $t, 0<t<\mathrm{T}, T$ is the sales cycle of fresh agricultural products, $\alpha$ is a sensitive factor of freshness to time, $\alpha>0, c$ is the maximum market demand rate which is unaffected by the sales price and freshness of products, $d$ is the sensitive factor of demand rate to sales price, and $p$ is the selling price of fresh agricultural products.

\subsection{Inventory Model of Farmers' Professional Cooperative.}

Taking the process of farmers' professional cooperative $j$ supplying to distribution center $k$ as an example: during the supply interval $\left\lfloor\left(x_{j k}-1\right) \cdot T_{j k}, x_{j k}, T_{j k}\right\rfloor$, the inventory level at time $t$ when the farmers' professional cooperative $j$ supplies to the distribution center $k$ is influenced by the productivity and the quantitative change of fresh agricultural products of farmers' professional cooperative. When combining it with the inventory change formula in classic metamorphic products proposed by Ghare and Schrader [29], we can get the following formula:

$$
\frac{\mathrm{d} I_{j k}(t)}{\mathrm{d} t}=\varepsilon_{j}-\theta_{1} \cdot I_{j k}(t)
$$

At the beginning of the supply interval $x_{j k}$, that is, when $t=\left(x_{j k}-1\right) \cdot T_{j k}$, the inventory of the farmers' professional cooperative $j$ is zero, so we get

$$
I_{j k}\left[\left(x_{j k}-1\right) \cdot T_{j k}\right]=0 .
$$

Combining equations (2) and (3), we can get the solution

$$
I_{j k}(t)=\frac{\varepsilon_{j}}{\theta_{1}} \cdot\left[1-e^{-\theta_{1} \cdot\left[t-\left(x_{j k}-1\right) \cdot T_{j k}\right]}\right] .
$$

It can be calculated that the total inventory of the farmers' professional cooperative $j$ supplying to the distribution center $k$ during the supply interval $\left\lfloor\left(x_{j k}-1\right) \cdot T_{j k}, x_{j k}, T_{j k}\right\rfloor$ is

$$
I_{j k}=\int_{\left(x_{j k}-1\right) \cdot T_{j k}}^{x_{j k} \cdot T_{j k}} I_{j k}(t) \mathrm{d} t=\frac{\varepsilon_{j}}{\theta_{1}} \cdot\left(T_{j k}-\frac{e^{-\theta_{1} \cdot T_{j k}}-1}{\theta_{1}}\right) .
$$

The production cost FS, inventory cost FK, and distribution expense FP of the farmers' professional cooperative $j$ during the supply interval $\left\lfloor\left(x_{j k}-1\right) \cdot T_{j k}, x_{j k}, T_{j k}\right\rfloor$ when the farmers' professional cooperative $j$ supplies to the distribution center $k$ are as follows:

$$
\begin{aligned}
\mathrm{FS}_{j k} & =\varepsilon_{j} \cdot P_{j} \cdot T_{j k}, \\
\mathrm{FK}_{j k} & =f_{j} \cdot I_{j k}, \\
\mathrm{FP}_{j k} & =C 2_{j k} \cdot \sum_{i=1}^{n} g_{j k i}^{1} \cdot y_{j k} \cdot y_{k i} .
\end{aligned}
$$

All costs above are generated during the process of single supply interval $x_{j k}$ and the supply of the farmers' professional cooperative $j$ to the distribution center $k$. Therefore, in the process of producing and supplying to all distribution centers, the total cost FC of all farmers' professional cooperatives is

$$
\mathrm{FC}_{j k}=\sum_{k=1}^{K} \sum_{j=1}^{m} y_{j k} a_{j k}(\mathrm{FS}+\mathrm{FK}+\mathrm{FP}) .
$$

In the process of producing and supplying to all distribution centers, the total revenue FY of all farmers' professional cooperatives is

$$
\mathrm{FY}=\sum_{i=1}^{n} \sum_{k=1}^{K} \sum_{j=1}^{m} y_{j k} \cdot y_{k i} \cdot a_{j k} \cdot P 1_{j} \cdot g_{j k i}^{1} .
$$

Thus, the total profit of all farmers' professional cooperatives, FL, during the process of producing and supplying to all distribution centers is

$$
\mathrm{FL}=\mathrm{FY}-\mathrm{FC} \text {. }
$$


3.2. Inventory Model of the Distribution Center. In the case that a distribution center $k$ supplies the product $j$ to supermarket $i$, the inventory level of distribution center $k$ is only influenced by the quantitative change loss during supply interval. Thus, the inventory level of product $j$ (supplied to supermarket $i$ ) of the distribution center $k$ at time $t$ during the supply interval $\left\lfloor\left(z_{j k i}-1\right) \cdot t_{j k i}, z_{j k i}, t_{j k i}\right\rfloor$ is as follows:

$$
\frac{\mathrm{dII}_{j k i}^{z_{j k i}}(t)}{\mathrm{d} t}=-\theta_{2} \cdot \mathrm{II}_{j k i}^{z_{j k i}}(t) .
$$

At the end of the supply interval $\left\lfloor\left(z_{j k i}-1\right) \cdot t_{j k i}, z_{j k i}, t_{j k i}\right\rfloor$, that is, when $t=z_{j k i} \cdot t_{j k i}$, the closing inventory of the fresh agricultural product $j$ (supplied to supermarket $i$ ) at distribution center $k$ is equal to the sum of the initial inventory $g_{j k i}^{z_{j k i}+1}$ of the next supply interval $\left\lfloor z_{j k i} \cdot t_{j k i},\left(z_{j k i}+1\right) \cdot t_{j k i}\right\rfloor$ and the quantity $g_{j k i}$ of product $j$ supplied by the distribution center $k$ to the supermarket $i$. Thus, we get

$$
\mathrm{II}_{j k i}^{z_{j k i}}\left(z_{j k i} \cdot t_{j k i}\right)=g_{j k i}^{z_{j k i}+1}+g_{j k i} \text {. }
$$

Combining equations (10) and (11) and using differential equation, we can get the solution

$$
\mathrm{II}_{j k i}^{z_{j k i}}(t)=\left(g_{j k i}^{z_{j k i}+1}+g_{j k i}\right) \cdot e^{-\theta_{2} \cdot\left(t-z_{j k i} \cdot t_{j k i}\right)} .
$$

When $t=\left(z_{j k i}-1\right) \cdot t_{j k i}$, we can get the initial inventory of the supply interval by substituting equation (12):

$$
\mathrm{II}_{j k i}^{z_{j k i}}\left(\left(z_{j k i}-1\right) \cdot t_{j k i}\right)=\left(g_{j k i}^{z_{j k i}+1}+g_{j k i}\right) \cdot e^{\theta_{2} \cdot t_{j k i}}
$$

According to the analysis of inventory level changes of distribution center in the previous example, we can see that the closing inventory, when $t=b_{j k i} \cdot t_{j k i}$, of the product in a distribution center at the supply interval (the last supply interval) is the single replenishment quantity of the supermarket replenished from the distribution center. Therefore,

$$
\begin{aligned}
g_{j k i} & =\mathrm{II}_{j k i}^{b_{j k i}}\left(b_{j k i} \cdot t_{j k i}\right)=\left(g_{j k i}^{b_{j k i}+1}+g_{j k i}\right) \cdot e^{-\theta_{2} \cdot\left(b_{j k i} \cdot t_{j k i}-b_{j k i} \cdot t_{j k i}\right)} \\
& =g_{j k i}+g_{j k i}^{b_{j k i}+1} .
\end{aligned}
$$

From the above formula, we get $g_{j k i}^{b_{j k i}+1}=0$.

When $t=\left(z_{j k i}-1\right) \cdot t_{j k i}$, the initial inventory of the supply interval $\left\lfloor\left(z_{j k i}-1\right) \cdot t_{j k i}, z_{j k i} \cdot t_{j k i}\right\rfloor$ is $g_{j k i}^{z_{j k i}}=\mathrm{II}_{j k i}^{z_{j k i}}$ $\left(\left(z_{j k i}-1\right) \cdot t_{j k i}\right)=\left(g_{j k i}+g_{j k i}^{z_{j k i}+1}\right) \cdot e^{\theta_{2} \cdot t_{j k i}}$, so the initial inventory $g_{j k i}^{b_{j k i}}$ of the supply interval $b_{j k i}$ can be obtained. That is,

$$
g_{j k i}^{b_{j k i}}=\left(g_{j k i}+g_{j k i}^{b_{j k i}+1}\right) \cdot e^{\theta_{2} \cdot t_{j k i}}=g_{j k i} \cdot e^{\theta_{2} \cdot t_{j k i}} .
$$

Thus,

$$
g_{j k i}^{b_{j k i}-1}=\left(g_{j k i}+g_{j k i}^{b_{j k i}}\right) \cdot e^{\theta_{2} \cdot t_{j k i}}
$$

By substituting equation (15) in equation (16), we can get

$$
\begin{aligned}
g_{j k i}^{b_{j k i}-1} & =\left(g_{j k i}+g_{j k i}^{b_{j k i}}\right) \cdot e^{\theta_{2} \cdot t_{j k i}}=\left(g_{j k i}+g_{j k i} \cdot e^{\theta_{2} \cdot t_{j k i}}\right) \\
& =g_{j k i}\left(e^{\theta_{2} \cdot t_{j k i}}+e^{2 \theta_{2} \cdot t_{j k i}}\right) .
\end{aligned}
$$

With the same method, we get

$$
\begin{aligned}
g_{j k i}^{b_{j k i}-2}= & \left(g_{j k i}+g_{j k i}^{b_{j k i}-1}\right) \cdot e^{\theta_{2} \cdot t_{j k i}}=g_{j k i} \\
& \cdot\left(e^{\theta_{2} \cdot t_{j k i}}+e^{2 \theta_{2} \cdot t_{j k i}}+e^{3 \theta_{2} \cdot t_{j k i}}\right), \\
g_{j k i}^{b_{j k i}-3}= & \left(g_{j k i}+g_{j k i}^{b_{j k i}-2}\right) \cdot e^{\theta_{2} \cdot t_{j k i}}=g_{j k i} \\
& \cdot\left(e^{\theta_{2} \cdot t_{j k i}}+e^{2 \theta_{2} \cdot t_{j k i}}+e^{3 \theta_{2} \cdot t_{j k i}}+e^{4 \theta_{2} \cdot t_{j k i}}\right) .
\end{aligned}
$$

After many times of iterations, we can get the initial inventory $g_{j k i}$ of the product $j$ (supplied to the supermarket $i)$ at the distribution center of the supply interval $z_{j k i}$ when $t=\left(z_{j k i}-1\right) \cdot t_{j k i}$, which can be expressed as

$$
g_{j k i}^{z_{j k i}}=g_{j k i} \cdot\left[e^{\theta_{2} \cdot t_{j k i}}+e^{2 \theta_{2} \cdot t_{j k i}}+\cdots+e^{\left(b_{j k i}-z_{j k i}+1\right) \cdot \theta_{2} \cdot t_{j k i}}\right] .
$$

Consequently, we get

$$
g_{j k i}^{z_{j l i}+1}=g_{j k i} \cdot\left[e^{\theta_{2} \cdot t_{j k i}}+e^{2 \theta_{2} \cdot t_{j k i}}+\cdots+e^{\left(b_{j k i}-z_{j k i}\right) \cdot \theta_{2} \cdot t_{j k i}}\right] .
$$

By substituting equation (20) in equation (12), we get

$$
\begin{aligned}
\operatorname{II}_{j k i}^{z_{j k i}}(t)= & g_{j k i} \cdot\left[1+\left(e^{\theta_{2} \cdot t_{j k i}}+e^{2 \theta_{2} \cdot t_{j k i}}+\cdots+e^{\left(b_{j k i}-z_{j k i}\right) \cdot \theta_{2} \cdot t_{j k i}}\right)\right] \\
& +e^{-\theta_{2} \cdot\left(t-z_{j k i} \cdot t_{j k i}\right)} .
\end{aligned}
$$

Therefore, the total inventory of the product $j$ (supplied to supermarket $i$ ) at the distribution center $k$ during the supply interval $z_{j k i}$ is

$$
\begin{aligned}
\mathrm{II}_{j k i}^{z_{j k i}}= & \int_{\left(z_{j k i}-1\right) \cdot t_{j k i}}^{z_{j k i} \cdot t_{j k i}} \mathrm{II}_{j k i}^{z_{j k i}}(t) \mathrm{d} t=-\frac{1}{\theta_{2}} \cdot g_{j k i} \\
& \cdot\left[1-e^{\left(b_{j k i}-z_{j k i}+1\right) \cdot \theta_{2} \cdot t_{j k i}}\right] .
\end{aligned}
$$

According to the analysis of inventory level changes of distribution center in the previous example, we can see that the initial inventory $g_{j k i}^{1}$ of the first supply interval $\left(0, t_{j k i}\right)$ (that is, when $z_{j k i}=1$ ) for distribution center $k$ to supply product $j$ to supermarket $i$ is the amount of replenishment from farmers' agricultural cooperatives:

$$
g_{j k i}^{1}=\mathrm{II}_{j k i}^{1}(0)=g_{j k i} \cdot\left(e^{\theta_{2} t_{j k i}}+e^{2 \theta_{2} t_{j k i}}+\cdots+e^{b_{j k i} \theta_{2} t_{j k i}}\right) .
$$

Moreover, within a single replenishment interval $x_{j k}$, the ordering cost DG, processing cost DJ, and inventory cost DK of the product (supplied to the supermarket) of the distribution center are as follows: 


$$
\begin{aligned}
\mathrm{DG}_{j k i} & =P 1_{j} \cdot g_{j k i}^{1}, \\
\mathrm{DJ}_{j k i} & =P 3_{j k} \cdot g_{j k i}^{1}, \\
\mathrm{DK}_{j k i} & =d_{j k} \cdot \sum_{z_{j k i}=1}^{b_{j k i}} \mathrm{II}_{j k i}^{z_{j k i}} .
\end{aligned}
$$

Distribution center is responsible for the transportation service of fresh agricultural products. In order to meet the needs of supermarket $i$ during a single replenishment interval $x_{j k}$, the distribution center $k$ replenishes the product $j$ with the quantity of $g_{j k i}^{1}$ from farmers' agricultural cooperatives and supplies the product with the quantity of $b_{j k i}$. $g_{j k i}$ to the supermarket $i$. So, the distribution cost, distribution revenue, and sales revenue can be calculated as follows:

$$
\begin{aligned}
& \mathrm{DP}_{j k i}=C 1_{j k} \cdot g_{j k i}^{1}+C 1_{j k} \cdot b_{j k i} \cdot g_{j k i}, \\
& \mathrm{DS}_{j k i}=C 2_{j k} \cdot g_{j k i}^{1}+C 2_{j k} \cdot b_{j k i} \cdot g_{j k i}, \\
& \mathrm{DX}_{j k i}=P 2_{j k} \cdot b_{j k i} \cdot g_{j k i} .
\end{aligned}
$$

All above costs and revenues are generated in the process that a distribution center $k$ supplies product $j$ to supermarket $i$ within a single replenishment interval $x_{j k}$. The total cost $D C$ generated by all distribution centers in the process of replenishment and supply is

$$
\mathrm{DC}=\sum_{i=1}^{n} \sum_{k=1}^{K} \sum_{j=1}^{m} y_{j k} \cdot y_{k i} \cdot a_{j k} \cdot(\mathrm{DG}+\mathrm{DJ}+\mathrm{DK}+\mathrm{DP}) .
$$

The total revenues generated by all distribution centers in the process of replenishment and supply is

$$
\mathrm{DY}=\sum_{i=1}^{n} \sum_{k=1}^{K} \sum_{j=1}^{m} y_{j k} \cdot y_{k i} \cdot a_{j k} \cdot(\mathrm{DS}+\mathrm{DX}) \text {. }
$$

We can now obtain the total profits generated by all distribution centers in the process of replenishment and supply as follows:

$$
\mathrm{DL}=\mathrm{DY}-\mathrm{DC}
$$

3.3. Inventory Model of the Supermarket. Assume a supermarket $i$ replenishes product $j$ from distribution center $k$. During the replenishment interval $\left\lfloor\left(z_{j k i}-1\right) \cdot t_{j k i}, z_{j k i} \cdot t_{j k i}\right\rfloor$, the changes of the inventory level of product $j$ (replenished from the distribution center $k$ ) in supermarket $i$ are influenced by the quantitative change loss and the demand rate. Thus, the amount of the inventory change of fresh agricultural products at time $t$ is as follows:

$$
\begin{aligned}
\frac{d \mathrm{III}_{j k i}(t)}{d t}= & -D_{j i}(t)-\theta_{3} \cdot \mathrm{III}_{j k i}(t)=-\lambda_{1} \cdot e^{-\alpha \cdot t} \\
& \cdot\left(c-d \cdot P_{j i}\right)-\theta_{3} \cdot \operatorname{III}_{j k i}(t) .
\end{aligned}
$$

When $t=z_{j 1 i} \cdot t_{j 1 i}$, the closing inventory of the supermarket $i$ in the replenishment interval $\left\lfloor\left(z_{j k i}-1\right) \cdot t_{j k i}, z_{j k i}\right.$. $\left.t_{j k i}\right\rfloor$ is 0 :

$$
\operatorname{III}_{j k i}\left(z_{j k i} \cdot t_{j k i}\right)=0 .
$$

Combining equations (29) and (30) and using differential equation, we can get

$$
\operatorname{III}_{j k i}(t)=\frac{\lambda_{1} \cdot\left(c-d \cdot P_{j i}\right)}{\theta_{3}-\alpha}\left[e^{-\theta_{3} \cdot t+z_{j k i} \cdot t_{j k i} \cdot\left(\theta_{3}-\alpha\right)}-e^{-\alpha \cdot t}\right] .
$$

Thus, in the replenishment interval $\left\lfloor\left(z_{j k i}-1\right) \cdot t_{j k i}, z_{j k i} \cdot t_{j k i}\right\rfloor$, the total inventory of the product $j$ (replenished from distribution center $k$ ) in supermarket $I$

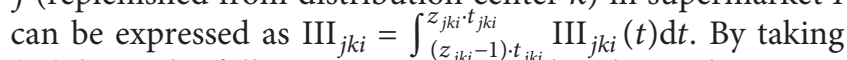
(31) here, the following equation can be obtained:

$$
\begin{aligned}
\operatorname{III}_{j k i}= & \frac{\lambda_{1} \cdot\left(c-d \cdot P_{j i}\right)}{\theta_{3}} \cdot\left[\left(\frac{1}{\alpha}-\frac{1}{\theta_{3}}\right)\right] \cdot e^{-\alpha \cdot z_{j k i} \cdot t_{j k i}} \\
& +\frac{1}{\theta_{3}} \cdot e^{t_{j k i}\left(\theta_{3}-\alpha \cdot z_{j k i}\right)}-\frac{1}{\alpha} \cdot e^{-\alpha \cdot t_{j k i} \cdot\left(z_{j k i}-1\right)} .
\end{aligned}
$$

During the replenishment interval $\left\lfloor\left(z_{j k i}-1\right) \cdot t_{j k i}, z_{j k i} \cdot t_{j k i}\right\rfloor$, the total market demand $x_{j k}$ of product $j$ (replenished from the distribution center $k$ ) in supermarket $i$ is as follows:

$$
\begin{aligned}
X_{j k i}= & \int_{\left(z_{j k i}-1\right) \cdot t_{j k i}}^{z_{j k i} \cdot t_{j k i}} D_{j i}(t) \mathrm{d} t=-\frac{\lambda_{1} \cdot\left(c-d \cdot P_{j i}\right)}{\alpha} \\
& \cdot\left[e^{-\alpha \cdot z_{j k i} \cdot t_{j k i}}-e^{-\alpha \cdot t_{j k i} \cdot\left(z_{j k i}-1\right)}\right] .
\end{aligned}
$$

According to the analysis of inventory level changes of supermarket in the previous example, the single replenishment amount $g_{j k i}$ of product $j$ of supermarket $i$ from distribution center $k$ is the initial inventory of the replenishment interval $z_{j k i}$. In other words, when $t=\left(z_{j k i}-1\right) \cdot t_{j k i}$, the following equation can be obtained:

$$
\begin{aligned}
g_{j k i}= & \operatorname{III}_{j k i}\left(\left(z_{j k i}-1\right) \cdot t_{j k i}\right)=\frac{\lambda_{1} \cdot\left(c-d \cdot P_{j i}\right)}{\theta_{3}-\alpha} \\
& \cdot\left[e^{t_{j k i} \cdot\left(\theta_{3}-\alpha \cdot z_{j k i}\right)}-e^{-\alpha \cdot t_{j k i} \cdot\left(z_{j k i}-1\right)}\right] .
\end{aligned}
$$

Thus, during the single replenishment interval $z_{j k i}$, the ordering cost SG, the inventory cost SK, and the distribution expenditure cost SP of product $j$ (replenished from the distribution center $k$ ) at supermarket $i$ are as follows:

$$
\begin{aligned}
& \mathrm{SG}_{j k i}=P 2_{j k} \cdot g_{j k i}, \\
& \mathrm{SK}_{j k i}=s_{j i} \cdot \mathrm{III}_{j k i}, \\
& \mathrm{SP}_{j k i}=C 2_{j k} \cdot g_{j k i} .
\end{aligned}
$$

All above costs are generated in the process that supermarket $i$ replenishes product $j$ from distribution center $k$ within the single replenishment interval $z_{j k i}$. The total cost 
SC generated by all supermarkets in replenishment and supply process is

$$
\mathrm{SC}=\sum_{i=1}^{n} \sum_{k=1}^{K} \sum_{j=1}^{m} y_{j k} \cdot y_{k i} \cdot a_{j k} \cdot b_{j k i}(\mathrm{SG}+\mathrm{SK}+\mathrm{SP}) .
$$

The total revenue SY generated by all supermarkets in the replenishment and supply process is

$$
\mathrm{SY}=\sum_{i=1}^{n} \sum_{k=1}^{K} \sum_{j=1}^{m} y_{j k} \cdot y_{k i} \cdot a_{j k} \cdot b_{j k i} \cdot P_{j i} \cdot X_{j k i} .
$$

From equations (36) and (37), we get the total profit SL that is generated by all supermarkets in the process of replenishing from all distribution centers and selling:

$$
\mathrm{SL}=\mathrm{SY}-\mathrm{SC} \text {. }
$$

3.4. Optimization of Integrated Inventory. In order to achieve the goal of optimal management of integrated inventory, the maximum value of the overall profit in the supply chain is considered as the objective function, that is,

$$
\max U\left(a_{j k}, b_{j k i}, g_{j k i}\right)=\mathrm{FL}+\mathrm{DL}+\mathrm{SL} \text {. }
$$

Three decision variables are involved in the maximization process, including $a_{j k}, b_{j k i}$, and $g_{j k i} \cdot a_{j k}$ is the number of times that a farmers' professional cooperative $j$ supplies to distribution center $k$ within the limited period $A . b_{j k i}$ is the number of times that a distribution center $k$ supplies product $j$ to supermarket $i$ within the period of $T_{j k}$, and $g_{j k i}$ is the single replenishment quantity that the supermarket $i$ replenishes the product $j$ from the distribution center $k$.

Given the objective of maximizing total profile, each stakeholder in the three-stage supply chain has to meet the minimum requirement regarding profits and inventory management, which can be expressed as follows:

$$
\left\{\begin{array}{l}
\mathrm{FL}, \mathrm{DL}, \mathrm{SL} \geq 0, \\
I_{j k}, \mathrm{II}_{j k i}^{z_{j k i}}, \mathrm{III}_{j k i} \geq 0 .
\end{array}\right.
$$

The aforementioned equation indicates that the profits of farmers' professional cooperatives, distribution centers, and supermarkets are not negative, while it indicates that the inventory of farmers' professional cooperatives, distribution centers, and supermarkets are not negative. Considering the complexity of the model and simplicity in algorithmic settings, this paper utilizes a genetic algorithm to find the optimal solutions $a_{j k}^{*}, b_{j k i}^{*}$, and $g_{j k i}^{*}$.

\section{Case Study}

4.1. Data and Parameters. The case study considers the supply chain of fresh agricultural products which is composed of three farmers' professional cooperatives, two distribution centers, and three supermarkets. The finite time period is eight days. The specific distribution process of the supply chain is described in Figure 1.

Based on an empirical investigation of the purchase and sale price of three types of fresh agricultural products, pomegranate, bayberry, and cherry, and combined with the data of inventory costs and production costs of fresh agricultural products in the literature (Fan and Shi) [21, 30], this paper obtains the data of unit inventory cost and unit production cost of the three types of fresh agricultural products. Moreover, the actual proportion of the distribution cost rate and the distribution price rate of the distribution center of company $M$ to the selling price of fresh agricultural products are obtained (the distribution cost rate is from $4.5 \%$ to $4.7 \%$ and the distribution price rate is from $5 \%$ to $5.5 \%)$. Detailed data arelated to fresh agricultural products of farmers' professional cooperatives, distribution centers, and supermarkets, as well as the parameters used in the calculation are presented in Tables 1-4.

\subsection{Implementation of the Genetic Algorithm}

4.2.1. Encoding Structure. This paper uses the real number coding of the genetic algorithm. According to the independent decision variables of the objective function, this paper uses segmented gene coding to express a group of orders (genotype individual). The genotype individual is composed of three loci. The three decision variables $a_{j k}, b_{j k i}$, and $g_{j k i}$ correspond to the gene values of the three loci, respectively. The changes in each group of genes affect the state of the genotype individuals.

4.2.2. Fitness Function. The fitness of chromosomes is $(\mathrm{FVAL})=-U$. In other words, the smaller the chromosome fitness, the larger value of the objective function.

4.2.3. Crossover Operation. This paper uses single-point crossover. For parent chromosomes, arbitrary selection of a crossover bit and exchange of all the gene bits from the selected crossover bit were carried out. For example, the gene $A$ is 110011 , the gene $B$ is 100101 , and if the crossover bit is three, then the new genes with exchange are 110101 and 100011 .

In this paper, the adaptive crossover operator was added to the design of the genetic algorithm. The crossover probability is adjusted according to the adaptive value function of each generation of individuals so that the whole evolution is carried out along the direction that is conducive to algorithm convergence. The formula is shown as follows:

$$
p_{i}=\frac{\left(f_{\max }-f_{i}\right)}{\left(f_{\max }-f_{\min }\right)},
$$

where $i$ represents an individual, $p_{i}$ is the crossover probability of the individual, $f_{i}$ is the individual fitness, and $f_{\min }$ and $f_{\max }$ are the minimum and maximum of population fitness, respectively.

4.2.4. Mutation Operation. Through the mutation operation of individuals (selected according to the mutation probability) in the population, the mutation probability of the gene value of the three loci in the chromosome is $1 / 3$. By generating random numbers, it is determined which loci has 


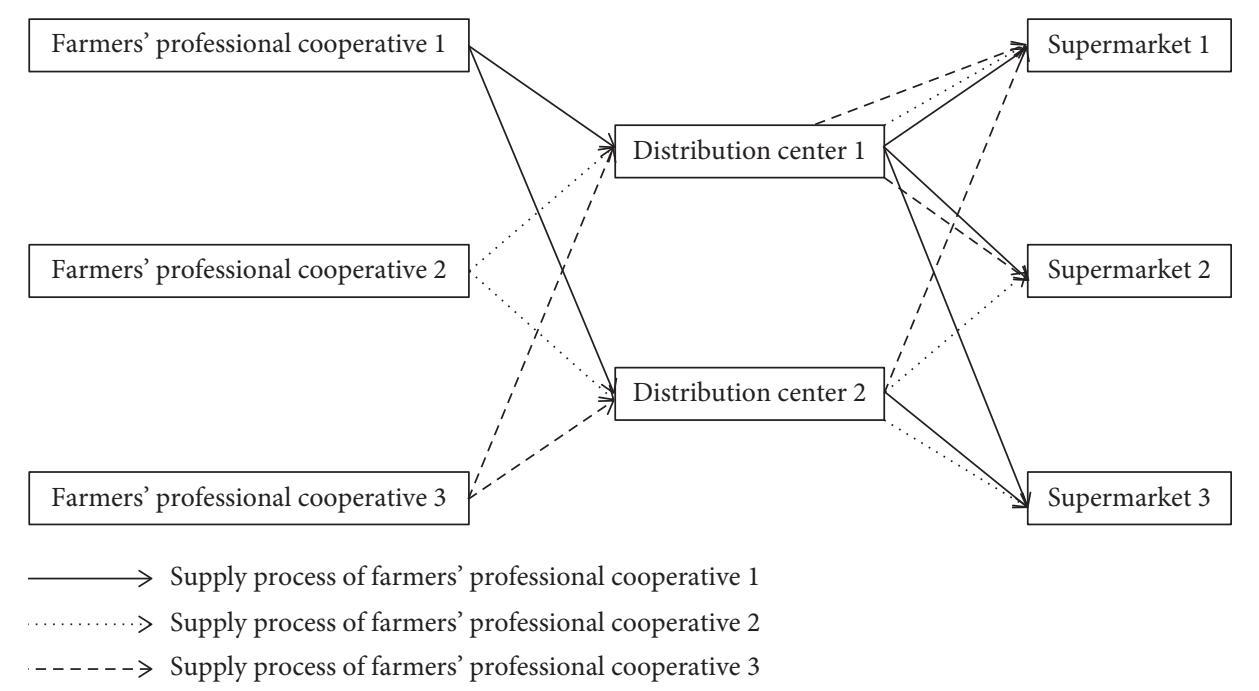

FIGURE 1: Supply process of agricultural superdocking.

TABLE 1: Data table of farmers' professional cooperatives.

\begin{tabular}{lcccc}
\hline \multirow{2}{*}{$A=8$} & Unit inventory cost & Unit production cost & Unit sales price & Productivity \\
& $f_{\mathrm{j}}$ & $P_{\mathrm{j}}$ & $51_{\mathrm{j}}$ & $\varepsilon_{\mathrm{j}}$ \\
\hline$j=1$ & 0.04 & 2 & 5.5 & 0.98 \\
$j=2$ & 0.12 & 8.2 & 13.5 & 0.95 \\
$j=3$ & 0.14 & 9.5 & 15 & 0.91 \\
\hline
\end{tabular}

Note. The unit of cost and price in this table is yuan per half a kilogram.

TABle 2: Data table of distribution centers.

\begin{tabular}{|c|c|c|c|c|c|c|c|c|c|c|}
\hline \multirow[b]{2}{*}{$A=8$} & \multicolumn{5}{|c|}{$k=1$} & \multicolumn{5}{|c|}{$k=2$} \\
\hline & $\begin{array}{c}\text { Unit } \\
\text { inventory } \\
\text { cost } \\
d_{\mathrm{jk}}\end{array}$ & $\begin{array}{c}\text { Unit } \\
\text { processing } \\
\text { cost } \\
P 3_{\mathrm{jk}}\end{array}$ & $\begin{array}{l}\text { Unit } \\
\text { sales } \\
\text { price } \\
P 2_{\mathrm{jk}}\end{array}$ & $\begin{array}{c}\text { Distribution } \\
\text { cost rate } \\
C 1_{j k}\end{array}$ & $\begin{array}{c}\text { Distribution } \\
\text { price rate } \\
C 2_{\mathrm{jk}}\end{array}$ & $\begin{array}{c}\text { Unit } \\
\text { inventory } \\
\text { cost } \\
d_{\mathrm{jk}}\end{array}$ & $\begin{array}{c}\text { Unit } \\
\text { processing } \\
\text { cost } \\
P 3_{\mathrm{jk}}\end{array}$ & $\begin{array}{l}\text { Unit } \\
\text { sales } \\
\text { price } \\
P 2_{\mathrm{jk}}\end{array}$ & $\begin{array}{c}\text { Distribution } \\
\text { cost rate } \\
C 1_{j k}\end{array}$ & $\begin{array}{c}\text { Distribution } \\
\text { price rate } \\
C 2_{\mathrm{jk}}\end{array}$ \\
\hline$j=1$ & 0.06 & 0.1 & 8.28 & 0.37 & 0.41 & 0.07 & 0.14 & 8.64 & 0.39 & 0.44 \\
\hline$j=2$ & 0.14 & 0.26 & 17 & 0.78 & 0.87 & 0.13 & 0.2 & 16.4 & 0.75 & 0.83 \\
\hline$j=3$ & 0.17 & 0.27 & 19.2 & 0.89 & 0.99 & 0.16 & 0.36 & 20 & 0.94 & 1.04 \\
\hline
\end{tabular}

Note. The unit of cost, price, and distribution price unit in this table is yuan per half a kilogram.

TABLE 3: Data table of supermarkets.

\begin{tabular}{|c|c|c|c|c|c|c|}
\hline \multirow[b]{2}{*}{$A=8$} & \multicolumn{2}{|c|}{$i=1$} & \multicolumn{2}{|c|}{$i=2$} & \multicolumn{2}{|c|}{$i=3$} \\
\hline & $\begin{array}{l}\text { Unit inventory cost } \\
s_{\mathrm{ji}}\end{array}$ & $\begin{array}{c}\text { Unit sales price } \\
P_{\mathrm{ji}}\end{array}$ & $\begin{array}{l}\text { Unit inventory cost } \\
s_{\mathrm{ji}}\end{array}$ & $\begin{array}{c}\text { Unit sales price } \\
P_{\mathrm{ji}}\end{array}$ & $\begin{array}{l}\text { Unit inventory cost } \\
s_{\mathrm{ji}}\end{array}$ & $\begin{array}{c}\text { Unit sales price } \\
P_{\mathrm{ji}}\end{array}$ \\
\hline$j=1$ & 0.1 & 25.8 & 0.1 & 20.3 & 0.12 & 24 \\
\hline$j=2$ & 0.17 & 35 & 0.16 & 32 & 0.21 & 34.5 \\
\hline$j=3$ & 0.37 & 50 & 0.38 & 60 & 0.3 & 53 \\
\hline
\end{tabular}

Note. The unit of cost and price in this table is yuan per half a kilogram.

mutated. When the random number is less than 0.333 , the gene value of the first gene loci of the chromosome is mutated. When the random number is greater than 0.667 , the gene value of the second loci of the chromosome is mutated. When the random number is between 0.333 and 0.667 , the gene value of the third loci of the chromosome is mutated.
4.2.5. Catastrophic and Sort Selection Operation. Some individuals in the population are selected by catastrophe probability to suffer catastrophe. This paper puts the progeny and parent population generated after the above operation of crossover, mutation, and catastrophic together and then ranks the fitness of population in order from small to large and selects the number of individuals of the original 
TABLE 4: Other parameters used in the equations.

\begin{tabular}{lcccccc}
\hline$\lambda_{1}$ & $\alpha$ & $c$ & $d$ & $\theta_{1}$ & $\theta_{2}$ & $\theta_{3}$ \\
\hline 0.98 & 0.2 & 300 & 5 & 0.15 & 0.18 & 0.2 \\
\hline
\end{tabular}

Note. $\lambda_{1}$ is the freshness of agricultural products when it arrives at the supermarket, $\alpha$ is a sensitive factor of freshness to time, $\alpha>0, c$ is the maximum market demand rate which is unaffected by the sales price and freshness of products, $d$ is the sensitivity factor of demand rate to sales price, and $\theta_{1}, \theta_{2}$, and $\theta_{3}$ represent the quantitative change coefficient of fresh agricultural products of farmers' agricultural cooperative, distribution center, and supermarket, respectively.

population size according to the fitness value of population from small to large, so as to generate new population.

4.2.6. Stop Condition. The stopping condition is set when the maximum number of iterations of population evolution is reached.

\section{Result Analysis}

5.1. Performance of the Genetic Algorithm. A program was made using Matlab to implement the genetic algorithm. The algorithm was run on a computer with an i5 processor and $4 \mathrm{~GB}$ memory. It takes about 25 seconds to converge. Figure 2 shows the results of the value of the objective function. One can see that the optimal solution is finally obtained, whereas the overall profit of the supply chain reaches the maximum.

5.2. Best Replenishment Strategy. By running the genetic algorithm, the best solution of replenishment was found. The results shown in Table 5 present the detailed distribution of different products between three stakeholders. More specifically, in the limited period of time, the farmers' professional cooperative 1 supplies products 5 times and 3 times to the distribution centers 1 and 2 , respectively. The distribution center 1 supplies the first type of fresh agricultural products 8,3 , and 10 times to the supermarkets 1,2 , and 3, respectively. Distribution center 2 supplies the first type of fresh agricultural products 5 times to supermarket 3 . Farmers' professional cooperative 2 supplies products 10 times and 1 time to the distribution centers 1 and 2, respectively. Distribution center 1 supplies the second type of fresh agricultural products 9 times to supermarket 1 . Distribution center 2 supplies the second type of fresh agricultural products 3 times and 1 time to the supermarkets 2 and 3, respectively. Farmers' professional cooperative 3 supplies products 5 times and 9 times to the distribution centers 1 and 2, respectively. Distribution center 1 supplies the third type of fresh agricultural products 4 times and 3 times to the supermarkets 1 and 2. Distribution center 2 supplies the third type of fresh agricultural products 9 times to supermarket 1 .

At the optimal level of replenishment, the maximum value of overall profit in the supply chain is 72,687 thousand yuan, among which the profit of all farmers' professional cooperatives is 69,586 thousand yuan, the profit of all distribution centers is 1,919 thousand yuan, and the profit of all supermarkets is 1,182 thousand yuan as shown in Table 6.

One can see from the results that when considering all kinds of costs, the fresh agricultural product with large value is, in general, replenished more frequently in supermarkets. It also means that, in the context of 'farmer' professional cooperative + distribution center + supermarket," the replenishment frequency of fresh agricultural products cannot be considered solely from commodity value, sales price, or distribution cost, but all kinds of factors in a comprehensive way.

5.3. Parametric Sensitivity Analysis. In order to analyze the influence of productivity and inventory cost of fresh agricultural products of farmers' professional cooperative on the profit of farmers' professional cooperative and the overall profit of the supply chain, a sensitivity analysis was conducted. More specifically, we examine the change of profit by changing the productivity, inventory cost, distribution profit rate, sales price, and freshness.

5.3.1. Influences of Productivity and Inventory Cost. Results presented in Table 7 show that the overall profit of farmers' professional cooperatives and supply chain increase when the productivity of fresh agricultural products increases. The change of productivity has a greater impact on the profits of farmers' professional cooperatives than on the overall profits of the supply chain. However, when the productivity continues to rise by $10 \%$, the amount of profit increases of farmers' professional cooperatives, and the whole supply chain declines. That is because the rise in productivity leads to the accumulation of fresh agricultural products and the increase in the inventory cost at all levels of the supply chain, which reduces the profits of farmers' professional cooperatives and the whole profits of the supply chain.

Moreover, the increase in inventory cost reduces the overall profits of farmers' professional cooperatives and the supply chain. Comparing with productivity, it can be found that when both inventory cost and productivity increase by $5 \%$, the impact of productivity on the farmers' professional cooperatives and the overall profit of the supply chain is greater than the impact of the inventory cost on both profits.

5.3.2. Influence of Distribution Profit Rate. Results of the changing distribution profit rate are shown in Table 8. It can be found that when the distribution profit rate of the distribution center increases by $5 \%$, the profit of the distribution center and the supply chain increases. Further, the change of the distribution profit rate has a greater impact on the profits of distribution centers than on the overall profits of the supply chain. But, when the distribution profit rate continues to rise by $10 \%$, the amount of increase in the profit of the whole supply chain shows a downward trend. This is mainly because the continuous increase of the distribution profit rate of the distribution center increases the distribution cost of other members of the supply chain, which 


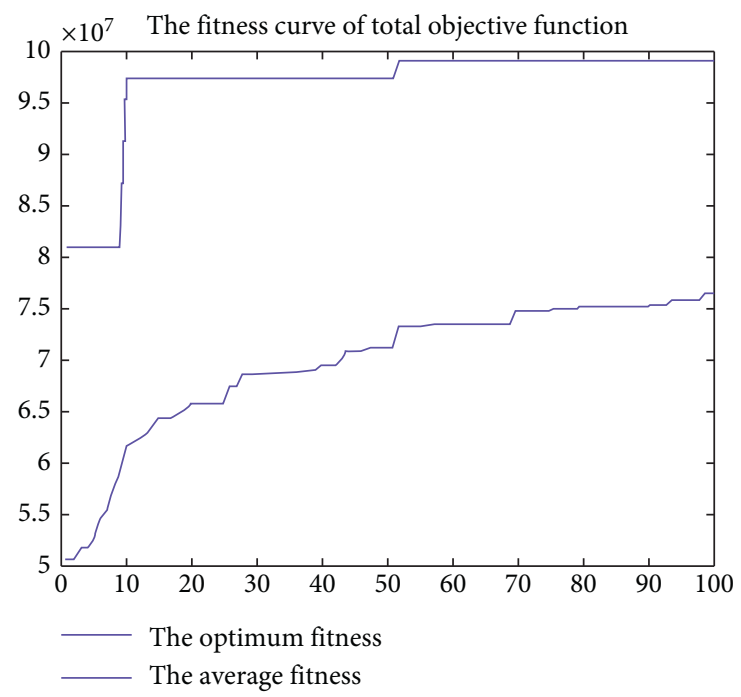

Figure 2: Fitness value of the genetic algorithm.

TABLE 5: The best replenishment strategy.

\begin{tabular}{|c|c|c|c|c|c|c|c|c|c|}
\hline \multicolumn{4}{|c|}{ Farmer' professional cooperative 1} & \multicolumn{3}{|c|}{$\begin{array}{l}\text { Farmer' professional } \\
\text { cooperative } 2\end{array}$} & \multicolumn{3}{|c|}{$\begin{array}{c}\text { Farmer' professional } \\
\text { cooperative } 3\end{array}$} \\
\hline $\begin{array}{l}a_{11} \\
5\end{array}$ & & & $\begin{array}{c}a_{12} \\
3\end{array}$ & $\begin{array}{c}a_{21} \\
10\end{array}$ & & & & & $\begin{array}{c}a_{32} \\
9\end{array}$ \\
\hline$b_{111}$ & $b_{112}$ & $b_{113}$ & $b_{123}$ & $b_{211}$ & $b_{222}$ & $b_{223}$ & $b_{311}$ & $b_{312}$ & $b_{321}$ \\
\hline 8 & 3 & 10 & 5 & 9 & 3 & 1 & 4 & 3 & 9 \\
\hline
\end{tabular}

TABLE 6: Results of the total profit.

\begin{tabular}{lccc}
\hline Farmer' professional cooperative & Distribution center & Supermarket & Supply chain system \\
\hline 69,586 & 1,919 & 1,182 & 72,687 \\
\hline
\end{tabular}

Note. The profit unit in this table is thousand yuan.

TABLE 7: Sensitivity analysis results-changes in productivity and inventory cost.

\begin{tabular}{|c|c|c|c|c|c|}
\hline \multirow{2}{*}{\multicolumn{2}{|c|}{ Amplitude of change }} & \multicolumn{2}{|c|}{ Productivity } & \multicolumn{2}{|c|}{ Inventory cost } \\
\hline & & $+5 \%$ & $+10 \%$ & $+5 \%$ & $+10 \%$ \\
\hline \multirow{2}{*}{ Farmers' professional cooperatives } & Profit after change & 7.6292 & 7.1919 & 6.4663 & 6.1392 \\
\hline & Amplitude of change & $+9.64 \%$ & $+3.35 \%$ & $-7.07 \%$ & $-11.78 \%$ \\
\hline \multirow{2}{*}{ Supply chain whole } & Profit after change & 7.9586 & 7.4967 & 6.7303 & 6.4216 \\
\hline & Amplitude of change & $+9.49 \%$ & $+3.14 \%$ & $-7.41 \%$ & $-11.65 \%$ \\
\hline
\end{tabular}

Note. The unit of profit in this table is ten million yuan.

reduces the profits of the whole supply chain. In practice, it might be beneficial to adjust the distribution profit rate appropriately for improving the efficiency of the supply chain members and overall benefits.

5.3.3. Influence of Sales Price and Freshness. The sensitivity analysis results based on the changing sales price and freshness are shown in Table 9. It can be seen that, in the initial rising period of the sales price of fresh agricultural products in supermarkets (a rise of 5\%), the profits of
TABLE 8: Sensitivity analysis results-changes in distribution profit rate.

\begin{tabular}{lccc}
\hline \multirow{2}{*}{ Amplitude of change } & \multicolumn{2}{c}{$\begin{array}{c}\text { Distribution } \\
\text { profit rate }\end{array}$} \\
& & $+5 \%$ & $+10 \%$ \\
\hline \multirow{2}{*}{ Distribution center } & Profit after change & 0.2023 & 0.2102 \\
& Amplitude of change & $+5.42 \%$ & $+9.54 \%$ \\
Supply chain whole & Profit after change & 7.3377 & 7.3220 \\
& Amplitude of change & $+0.95 \%$ & $+0.73 \%$ \\
\hline
\end{tabular}

Note. The unit of profit in this table is ten million yuan. 
TABLe 9: Sensitivity analysis results-changes in sales price and freshness.

\begin{tabular}{|c|c|c|c|c|c|}
\hline \multirow{2}{*}{\multicolumn{2}{|c|}{ Amplitude of change }} & \multicolumn{2}{|c|}{ Sales price } & \multicolumn{2}{|c|}{ Freshness } \\
\hline & & $+5 \%$ & $+10 \%$ & $-5 \%$ & $-10 \%$ \\
\hline \multirow{2}{*}{ Supermarket } & Profit after change & 0.1216 & 0.0980 & 0.1094 & 0.0871 \\
\hline & Amplitude of change & $+2.88 \%$ & $-17.09 \%$ & $-7.45 \%$ & $-26.31 \%$ \\
\hline \multirow{2}{*}{ Supply chain whole } & Profit after change & 7.4175 & 7.2140 & 7.2204 & 7.1085 \\
\hline & Amplitude of change & $+1.98 \%$ & $-0.75 \%$ & $-0.66 \%$ & $-2.20 \%$ \\
\hline
\end{tabular}

Note. The unit of profit in this table is ten million yuan.

supermarkets and the whole profits of the supply chain have been increased. Furthermore, the range of the rising supermarket profits is greater than that of the overall profits of the supply chain. But, when the sales price continues to increase by $10 \%$, the market demand rate of fresh agricultural products is negatively associated with the sales price in the sense that decreasing demand rate reduces the profits of supermarkets and the overall profit of the supply chain.

In addition, the decrease of freshness of agricultural products leads to the decline of supermarket profits and the overall profit of the supply chain. When freshness equals to the amplitude of drop, the profit of supermarket and the overall profit of the supply chain decrease in an upward trend. Through the horizontal comparison with the changes of sales price, it can be seen that the change in freshness of agricultural products has a larger impact than the change in sales prices on the overall profits of supermarkets and the supply chain.

\section{Summary and Conclusions}

Based on the agricultural superdocking mode, this paper investigated the inventory management issue of fresh agricultural products in order to improve the whole operational process of the supply chain. The model incorporates the main influencing factors of market demand to describe the inventory change supply chain members in detail, which also helps improve consumers' perception of purchasing decisions. The coordination mechanism identified through the case study enriches the theoretical understanding of supply chain coordination and optimization.

More specifically, the agricultural superdocking mode penetrates in the simulation of the logistics operation process for fresh agricultural products supply chain, whereas an integrated inventory pattern of fresh agricultural products involving farmers' professional cooperatives, distribution centers, and supermarkets was determined considering the diversity of supply chain members at all levels. Study the impact of changes of inventory level of supply chain members on the whole supply chain profit. Considering that the market demand of fresh agricultural products is affected by the freshness and sales price, an optimal supply chain optimization not only improves the overall profit but also consumer values, achieving a win-win situation.

The main research work and achievements of this paper include as follows.

The integrated inventory model of the three-level supply chain of fresh agricultural products considers that the market demand rate of fresh agricultural products is influenced by freshness and sales price at the same time, and distribution centers are responsible for the processing, transporting, and distribution of fresh agricultural products and participate in the sales of products. The best supply and replenishment strategy of each member of the supply chain were obtained by maximizing the overall profit of the supply chain. Moreover, the sensitivity analysis puts forward some practical suggestions on the whole operation planning of supply chains.

In spite that a three-level supply chain network structure was established in the current study, the subnetworks among the levels and the nodes at each level of the supply chain were not addressed yet. The supply chain optimization of complex structures may be a natural extension of future research. Moreover, the current study assumes a fixed demand. However, the actual demand can be highly uncertain. Thus, future research may further study the inventory optimization under stochastic demand.

\section{Data Availability}

The data used to support the findings of this study are included within the article (Tables 1-4).

\section{Conflicts of Interest}

The authors declare that they have no conflicts of interest.

\section{Acknowledgments}

This work was supported by EU H2020 Project (AMD no. 777742-56), the National Natural Science Foundation of China (no. 71301108), the Ministry of Education of $\mathrm{Hu}-$ manities and Social Science Project (no. 18YJC630061), the China Postdoctoral Science Foundation Funded Project (no. 2019M661085), the General Program of National Natural Science Foundation of China (no. 71571025), and the Social Science Planning Fund Project of Liaoning Province (no. L19BJL005).

\section{References}

[1] M. Shin, H. Lee, K. Ryu, Y. Cho, and Y.-J. Son, "A two-phased perishable inventory model for production planning in a food industry," Computers \& Industrial Engineering, vol. 133, pp. 175-185, 2019.

[2] F. Li, Optimization Research on Integrated Inventory of Fresh Agricultural Products Supply Chain Based on "Agricultural Super-docking" Mode, Dalian Maritime University, Dalian, Liaoning, 2018. 
[3] J.-F. Li and Z.-X. Wang, "Research on coordination of multiproduct "agricultural super-docking" supply chain," Procedia Manufacturing, vol. 30, pp. 560-566, 2019.

[4] J. Guo and L. Xu, "Stability of farmer cooperatives "agriculture-supermarket docking" and its impact factor analysis," Journal of Business Economics, vol. 10, pp. 13-23, 2017.

[5] H. Yang, Y. Sun, and J. Ma, "A research on the order default for "farmer-supermarket direct-purchase"," Science Research Management, vol. 40, no. 6, pp. 225-233, 2019.

[6] Qi Zheng, T. Fan, and L. Zhang, "Revenue-sharing contract of fresh product in "farming-supermarket docking" mode," Journal of Systems \& Management, vol. 28, no. 4, pp. 742-751, 2019.

[7] J. Yang, "Profit distribution of farmer-supermarket direct purchase model with unequal power," Issues in Agricultural Economy, vol. 7, pp. 93-102, 2019.

[8] H. Yao and X. Ran, "Profit allocation in agricultural supply chain considering risk factors," International Journal of Manufacturing Technology and Management, vol. 33, no. 3-4, pp. 176-188, 2019.

[9] J. Chen, H. Dai, and Q. Sun, "An empirical study on the relationship between farmers' psychological contract and channel opportunistic behavior under "agricultural super docking" mode," Journal of Agrotechnical Economics, vol. 7, pp. 41-51, 2017.

[10] J. Fan and Z. Zhang, "An empirical study on the development trend of intensive circulation of fresh agricultural products under the condition of "agricultural super docking", Journal of Commercial Economics, vol. 2, pp. 122-124, 2018.

[11] J. Wang, Research on the Fruit Inventory Control of Fresh Supermarket Chains in the Background of "Farmer-supermarket Docking", Jilin University, Changchun, China, 2017.

[12] X. Wang, P. Liu, and S. Wang, "Inventory ordering and pricing policy for cold chain items with Weibull survival and death characteristics," Operations Research and Management Science, vol. 26, no. 1, pp. 45-52, 2017.

[13] Y. Tang, T. Fan, and S. Liu, "Pricing and inventory decisionmaking for fresh agricultural products with strategic consumers," Chinese Journal of Management Science, vol. 26, no. 11, pp. 105-113, 2018.

[14] L. Shen, K. Govindan, A. B. Borade, A. Diabat, and D. Kannan, "An evaluation of vendor managed inventory practices from small and medium Indian enterprises," Journal of Business Economics and Management, vol. 14, no. 1, pp. S76-S95, 2013.

[15] H. Liu, J. Zhang, C. Zhou, and Y. Ru, "Optimal purchase and inventory retrieval policies for perishable seasonal agricultural products," Omega, vol. 79, pp. 133-145, 2018.

[16] S. Banerjee and S. Agrawal, "Inventory model for deteriorating items with freshness and price dependent demand: optimal discounting and ordering policies," Applied Mathematical Modelling, vol. 52, pp. 53-64, 2017.

[17] L. Janssen, A. Diabat, J. Sauer, and F. Herrmann, "A stochastic micro-periodic age-based inventory replenishment policy for perishable goods," Transportation Research Part E: Logistics and Transportation Review, vol. 118, pp. 445-465, 2018.

[18] S. Wang, Y. Jiang, and J. Mou, "Inventory and pricing decision of an integrated cold chain based on freshness," Chinese Journal of Management Science, vol. 26, no. 7, pp. 132-141, 2018.

[19] J. Mou, M. Zhang, and S. Wang, "Inventory strategy of fresh agricultural products' freshness and price influencing demand together," Statistics \& Decision, vol. 35, no. 6, pp. 54-57, 2019.
[20] K. Chen and T. Xiao, "Pricing and replenishment policies in a supply chain with competing retailers under different retail behaviors," Computers \& Industrial Engineering, vol. 103, pp. 145-157, 2017.

[21] X. Fan, The Analysis of Integrated Three-Echelon Cold Chain Inventory-Distribution Optimization Model Based on Distribution Center, Yantai University, Yantai, China, 2016.

[22] Y. Jiang, An Integrated Three-Echelon Inventory Model and Empirical Analysis Based on Distribution Center, Yantai University, Yantai, China, 2014.

[23] Z. Dai, F. Aqlan, and K. Gao, "Optimizing multi-echelon inventory with three types of demand in supply chain," Transportation Research Part E: Logistics and Transportation Review, vol. 107, pp. 141-177, 2017.

[24] G. Xu and J. Feng, "Simulation-based optimization of control policy on multi-echelon inventory system for fresh agricultural products," International Journal of Agricultural and Biological Engineering, vol. 12, no. 2, pp. 184-194, 2019.

[25] S. C. Tsai and S. T. Chen, "A simulation-based multi-objective optimization framework: a case study on inventory management," Omega, vol. 70, pp. 148-159, 2017.

[26] X. Ma, S. Wang, S. M. N. Islam, and X. Liu, "Coordinating a three-echelon fresh agricultural products supply chain considering freshness-keeping effort with asymmetric information," Applied Mathematical Modelling, vol. 67, pp. 337-356, 2019.

[27] W. Zhao and D. Wang, "Simulation-based optimization on control strategies of three-echelon inventory in hybrid supply chain with order uncertainty," IEEE Access, vol. 6, pp. 54215-54223, 2018.

[28] S. M. Mousavi, A. Bahreininejad, and S. N. Musa, "A modified particle swarm optimization for solving the integrated location and inventory control problems in a two-echelon supply chain network," Journal of Intelligent Manufacturing, vol. 28, no. 1, pp. 191-206, 2017.

[29] P. M. Ghare and G. F. Schrader, "A model for exponentially decaying inventory," Journal for Industrial Engineering, vol. 14, no. 5, pp. 238-143, 1963.

[30] Y. Shi, Distribution Ordering Strategy and Supply Chain Coordination Based on Fresh Agricultural Product Metamorphic Loss, Nanjing University of Science \& Technology, Nanjing, China, 2017. 